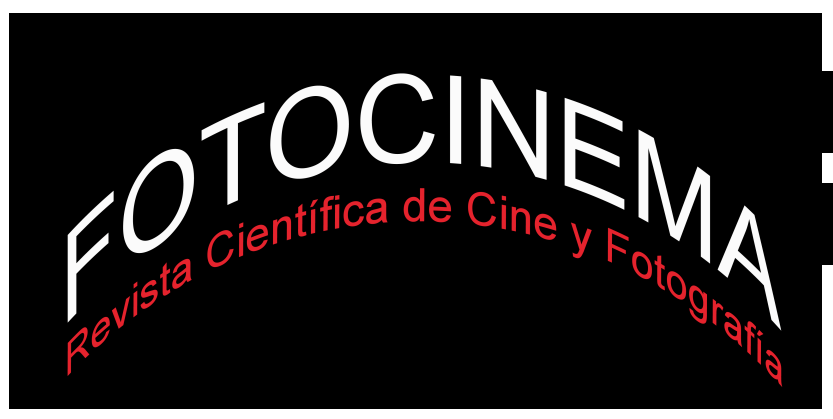

\title{
ARTE Y FOTOGRAFÍA DIGITAL. UNA APROXIMACIÓN AL ESTUDIO DE ALGUNAS TENDENCIAS CREATIVAS DE LA FOTOGRAFÍA DIGITAL EN EL CONTEXTO DE LA PRODUCCIÓN ARTÍSTICA
}

\section{ART AND DIGITAL PHOTOGRAPHY. AN APPROACH TO THE STUDY OF SOME CREATIVE DIGITAL PHOTOGRAPHY TRENDS IN ART PRODUCTION CONTEXT}

\author{
Javier Marzal Felici \\ Universitat Jaume I \\ marzal@uji.es
}

\begin{abstract}
Resumen:
Nos proponemos presentar en las siguientes páginas algunas reflexiones sobre la incidencia de la tecnología digital en el campo de la fotografía, en concreto en el contexto de la creación artística. En primer lugar, se articula una breve revisión de las principales dificultades que plantea la acotación de un territorio creativo como el de la "fotografía artística". A continuación se propone un recorrido, necesariamente parcial y subjetivo, a través de la obra fotográfica de diferentes creadores contemporáneos, con el fin de determinar algunos rasgos característicos de la creación digital en el mundo del arte fotográfico. El propósito de este trabajo es subrayar cómo la transformación digital de la fotografía ha multiplicado sus posibilidades expresivas y narrativas, $\mathrm{y}$ ha convertido al medio fotográfico en un campo fértil, no sólo para la creación artística, sino sobre todo para la reflexión en torno a la naturaleza de la imagen y de la cultura visual contemporánea.
\end{abstract}

\section{Palabras clave:}

Fotografía artística; fotografía digital; autorreflexividad; arte; creación; espectáculo.

Keywords:

Artistic photography; digital photography; auto-reflexivity; art; creation; spectacle. 


\section{Algunas notas sobre la fotografía como arte}

Antes de presentar una revisión panorámica sobre las tendencias creativas de la fotografía digital en el ámbito de la producción artística, parece necesario enfrentarnos al propio concepto de arte y, más específicamente, a la noción de "fotografía artística”. Sin duda, se trata de una cuestión que, en sí misma, encierra una gran complejidad que no se puede zanjar en unas pocas páginas, y a la que nos hemos enfrentado en un estudio anterior, titulado Cómo se lee una fotografía. Interpretaciones de la mirada (Marzal, 2007).

A modo de síntesis, cabría destacar una serie de ideas fundamentales que nos pueden ser de ayuda para acotar lo que entendemos como "fotografía artística”, esto es, qué queremos decir o a qué nos referimos cuando afirmamos que una fotografía o serie de fotografías puede enmarcarse en el campo de la producción artística. Previamente, cabe asumir que la adscripción de una fotografía (o cualquier otro tipo de artefacto material, sea el soporte que sea) a la categoría de obra de arte es siempre un tipo de operación que, por un lado, depende del propio espectador y, por otro, de las condiciones sociológicas, económicas y políticas que determinan la valoración de las obras de arte en cada época y tiempo histórico en las que éstas surgen. Esta variabilidad del concepto de arte está en la base de la dificultad extrema para poder enunciar una definición de arte válida para todo tiempo y lugar. Sin embargo, esto no significa que no podamos esbozar una serie de líneas principales a seguir por el historiador o teórico del arte y de la imagen en el estudio del texto artístico, fotográfico en nuestro caso.

Por un lado, es muy importante dirigir nuestra atención hacia el estudio de las condiciones de producción de las obras de arte, esto es, al análisis de las condiciones sociológicas, económicas, políticas, religiosas e incluso biográficas que rodean la aparición de la obra de arte. Es igualmente importante prestar atención al estudio de la tecnología empleada en la época, condiciones de producción sometidas al desarrollo histórico. En el caso del tema que nos ocupa, el análisis de las tendencias creativas de la fotografía digital en el contexto de la producción artística, es realmente muy difícil 
poder dar cuenta, de un modo mínimamente riguroso, del complejo panorama de tendencias que existen en la actualidad. Al prestar atención a las tendencias desarrolladas en los últimos veinticinco años aproximadamente (la fecha de inicio de la fotografía digital cabe cifrarla en la generalización del programa Adobe Photoshop, hacia 1990), realmente es muy difícil ofrecer una visión panorámica que dé cuenta de la extraordinaria heterogeneidad de prácticas significantes que han aparecido en estos últimos años. La producción fotográfica, con ayuda de las tecnologías digitales, es un objeto de estudio inabarcable, que debe ser abordado por un amplio equipo de investigadores.

En segundo lugar, es fundamental atender a las condiciones de recepción de la obra de arte. En el estudio de las tendencias creativas en el campo de la fotografía artística digital, nos encontramos con algunas claves fundamentales: el consumo de la fotografía digital, incluida la fotografía artística, se realiza actualmente, no sólo a través de las instituciones tradicionales del arte (museos, exposiciones en galerías, fundaciones, centros culturales, publicación de catálogos impresos, etc.), sino que ésta se produce principalmente a través de internet, medio de distribución y difusión de la obra artística contemporánea que ha pasado a convertirse, quizás, en el más relevante del panorama cultural contemporáneo. Por otro lado, el consumidor actual de arte suele tener un nivel cultural medio-alto o alto y es usuario de las nuevas tecnologías, de tal modo que consume arte a través de pantallas.

En tercer lugar, el trabajo historiográfico y del teórico del arte (y de la imagen) no puede dejar de lado el análisis de la obra de arte y del texto fotográfico en su estricta materialidad física, atendiendo así a las características formales de la obra de arte (textura, color, iluminación, formas, líneas, etc.), a sus elementos estructurales (composición de la imagen, equilibrio, orden icónico, organización de la lectura, etc.), los contenidos y temas que desarrollan (mediante el análisis iconológico y de simbologías), etc. 
En cuarto lugar, como ya advertíamos en nuestra investigación sobre el análisis de la imagen fotográfica, uno de los problemas más debatidos en relación a la naturaleza de la obra de arte es el de la intencionalidad. Algunos autores como Fernández Arenas destacan como un rasgo inherente al objeto artístico "la intención de su autor de comunicar algo" (Fernández Arenas, 1984: 24). Otros estudiosos como Panofsky situan, en cambio, esta intencionalidad en la instancia receptora, cuando define la obra de arte como un "objeto que, fabricado por el hombre, reclama ser estéticamente experimentado" (Panofsky, 1979: 29). Al margen de las diferentes posturas que conducen a proponer como criterio interpretativo de la obra de arte, respectivamente, al autor o al receptor (público o crítico), podemos reconocer una intencionalidad que procede simultáneamente de ambas instancias. Ciertamente, la obra de arte constituye un punto de encuentro de diversas intencionalidades. No debemos olvidar que la intención es una actitud que viene condicionada históricamente, y que encuentra una concreción directa en las formas artísticas. En el estudio de las tendencias creativas de la fotografía digital en el contexto de la producción artística, se puede obtener mucha información sobre la obra fotográfica que analizamos, al tratar autores que están vivos y con la mayoría de los cuales incluso no resultaría difícil establecer contacto para conocer sus opiniones sobre su propia obra fotográfica.

Finalmente, se considera fundamental recordar que Umberto Eco ha atribuido la dificultad para determinar el carácter artístico de cualquier artefacto material a la variabilidad histórica a la que antes nos hemos referido. Además de afirmar el carácter convencional de la obra de arte, de tratarse de una producción cultural, Umberto Eco ha señalado dos rasgos definitorios del arte: la ambigüedad y la autorreflexividad, y que creemos que mantienen una plena vigencia, en especial cuando nos enfrentamos al estudio de artefactos materiales tan actuales como la producción artística sobre el soporte fotográfico digital. El primer elemento, la ambigüedad, pretende poner de relieve el carácter abierto de toda obra de arte, su 
estructura abierta que hace posible un permanente e inagotable repertorio de interpretaciones de la obra de arte, que le llevan a proclamar la ausencia de una estructura que en el estudio de la obra de arte pudiéramos llegar a establecer (Eco, 1974, 1981). La autorreflexividad remite a la capacidad que tiene toda obra de arte para poder hablar de su particular configuración y de su poder para cuestionar qué es el propio arte. En última instancia, toda obra de arte somete a interrogación la naturaleza del arte, planteando nuevas preguntas y creando un conflicto en el propio público entre lo que ya conoce (las obras de arte conocidas por el receptor) y los nuevos artefactos artísticos a los que se enfrenta.

La delimitación sociocultural que determina el horizonte de expectativas del público en la recepción de la obra de arte remite a la dialéctica tradiciónvanguardia, una constante que hace más pertinente, si cabe, la perspectiva histórica en el estudio de la obra de arte, y que tiene plena vigencia aunque estemos abordando un objeto de estudio como la producción fotográfica artística digital. La noción de autorreflexividad está estrechamente vinculada al concepto de intertextualidad, a la relación entre el arte contemporáneo y la existencia de una extensa tradición que el receptor debe conocer para poder descifrar el significado de la obra de arte. En efecto, numerosas manifestaciones culturales -y artísticas- de los actuales medios de masas exigen un conocimiento profundo de la historia del arte y, en especial, del arte contemporáneo. En nuestro campo de trabajo concreto, es imposible comprender muchas técnicas de fotomontaje de la fotografía publicitaria o de la fotografía artística contemporánea sin conocer, por ejemplo, la obra fotográfica de John Heartfield, Raoul Halsmann, Josep Renau, pero también de otros fotógrafos clásicos como Oscar Rejlander, Henry Peach Robinson, Edward Muybridge, etc. Historiar estos fenómenos culturales o, en nuestro caso, ofrecer un modesto recorrido panorámico de tendencias creativas en los últimos veinticinco años, constituye una necesidad para su comprensión, especialmente cuando el repertorio de objetos artísticos, especialmente en el 
campo de la fotografía artística, ha alcanzado en la actualidad una extensión realmente enorme.

Finalmente, no debemos olvidar, en este apresurado repaso de las claves principales de nuestra caracterización de la obra de arte, que su valor está sometido también (y, especialmente, en los tiempos que corren) al dictado de las reglas del mercado. El valor de los objetos artísticos es establecido por expertos y especialistas como historiadores de arte, críticos, coleccionistas, marchantes de arte, etc. Es importante destacar que la valoración de estos expertos depende en gran medida de grupos sociales realmente reducidos, cuya relación con el poder económico (y también, con el poder político, como ocurre con demasiada frecuencia en España), es notable. Existe muchas veces una divergencia sustancial entre la valoración que hace el espectador profano y la valoración del experto. De este modo, una caracterización de la obra de arte, y del valor artístico de la fotografía, no puede omitir la naturaleza del arte como mercancía, en una sociedad que se rige poderosamente por unas leyes de mercado - la ley de la oferta y la demanda-, si bien es cierto que "no hay que confundir el valor artístico de una obra con su valor económico" (Furió, 1990: 19). Por otra parte, la consideración del arte como mercancía puede enmascarar la función lúdica del arte, es decir, el goce estético que se deriva de la fruición con la obra de arte (Barthes, 1973).

\section{Tendencias creativas de la fotografía digital en el contexto de la producción artística}

A nuestro juicio, las tecnologías digitales han ampliado muy considerablemente las posibilidades expresivas y narrativas del medio fotográfico, entre las que destacamos las siguientes. 


\subsection{La invisibilización de la enunciación como deconstrucción}

Por un lado, las tecnologías digitales permiten borrar las huellas enunciativas de la producción fotográfica, esto es, son herramientas idóneas para ocultar el carácter de artificio que posee toda representación fotográfica. De este modo, una serie de fotografías puede contar una historia absolutamente falsa, con la máxima credibilidad posible. Tal vez uno de los creadores que ha empleado las tecnologías digitales en el campo de la fotografía en este sentido, de forma más frecuente y muy coherentemente, es Joan Fontcuberta. Su serie Fauna secreta (1989), realizada cuando todavía no existían las tecnologías digitales aplicadas a la fotografía, ya anticipaba una línea de trabajo hacia la construcción de ficciones que simulan la realidad, sin apenas fisuras. Así pues, nos hallamos ante la invisibilización de la instancia enunciativa que podemos ver perfectamente reflejados en numerosos trabajos de este autor: la Serie Sputnik (1997), la serie Karelia. Milagros y compañía (2002) y la serie Deconstruyendo Osama (2007). Para que las series de fotografías sean coherentes y verosímiles, el autor construye un relato, de cierta complejidad, que le permite contextualizar y "anclar" la credibilidad de las imágenes. Por otro lado, estamos ante una serie de prácticas artísticas, que que tienen una clara vocación política, como afirma Jacques Terrasa (2006).

En la Serie Sputnik (1997), Fontcuberta reconstruye la supuesta historia de un cosmonauta, cuya misión fracasó en plena guerra fría, en lo que se conoce como la "carrera espacial" por la llegada a la Luna. El falso reportaje, impecablemente construido, le sirve para denunciar la existencia de aparatos de propaganda, que manipulan y reescriben la historia, si es necesario falsificando o "borrando" la presencia de sus protagonistas en las fotografías, que funcionan en estos contextos como "huellas" o pruebas fehacientes de lo acontecido (F1). El relato periodístico que consiguió construir Fontcuberta en Sputnik fue tan creíble que el programa de televisión Cuarto Milenio se hizo 
eco de esta historia, lo que sirvió para mostrar la credulidad en la que se basan programas como éste.

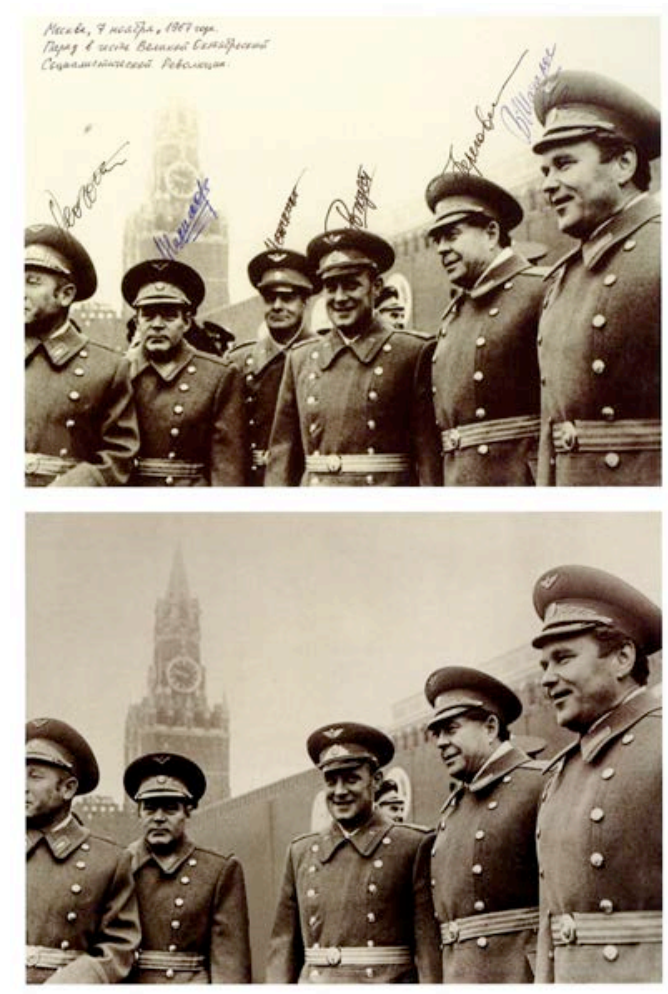

F1: Retratos originales de un grupo de cosmonautas soviéticos de 1967 y 1997 , respectivamente, Serie Sputnik

En el caso de la Serie Karelia. Milagros y compañía (2002), Fontcuberta construye una ficción que se camufla en una suerte de "reportaje periodístico", que en sí misma constituye una denuncia del fanatismo religioso y el sectarismo. La historia se construye a partir de un anuncio que supuestamente descubre el autor en el periódico de mayor difusión de Finlandia, el Helsingin Sanomat, en el que había un anuncio del Monasterio de Valhamönde, donde se imparten cursos de esoterismo, para desarrollar capacidades sobrehumanas. Como señala el propio Fontcuberta, "la religión [sigue] siendo un arma cargada de futuro: el control de las almas predispone al dominio del mundo, y muchos embaucadores y falsos profestas han intentado sacar tajada de la fuerza irracional de los sentimientos religiosos 
para su mercantilización económica y su instrumentalización política”. En definitiva, esta serie de relatos-fotografías se propone denunciar cómo el ocultismo y la parapsicología están cobrando una importancia muy relevante en nuestra sociedad. Se trata de discursos que también son utilizados para el control social, a través del miedo a la muerte de la especie humana. Como es habitual en Fontcuberta, la historia que cuenta está cargada de mucho humor e ironía, como se puede apreciar en la serie de imágenes.

Finalmente, en la serie Deconstruyendo Osama (2007) (F2), también titulada "La verdad sobre el caso Manbaa Mokfhi", Joan Fontcuberta nos propone una historia, bajo el formato de reportaje de investigación supuestamente realizado por dos fotoperiodistas de la agencia de noticias árabe Al-Zur (que obviamente no existe), Mohammed ben Kalish Ezah y Omar ben Salaad, que siguieron a un supuesto personaje seguidor de AlQaeda, y de Osama Bin Laden, el doctor Fasqiyta Ul-Junat. El verdadero nombre del doctor era Manbaa Mokfhi, que, en realidad, era un actor contratado por no se sabe quien para interpretar el papel de terrorista en operaciones en Afganistán e Irak. De nuevo, Fontcuberta nos coloca ante una historia periodística que cuestiona la crebibilidad de los discursos informativos sobre la lucha internacional contra el terrorismo árabe, mostrando cómo se contruyen los discursos propagadísticos, que hurden las agencias occidentales y los propios terroristas.

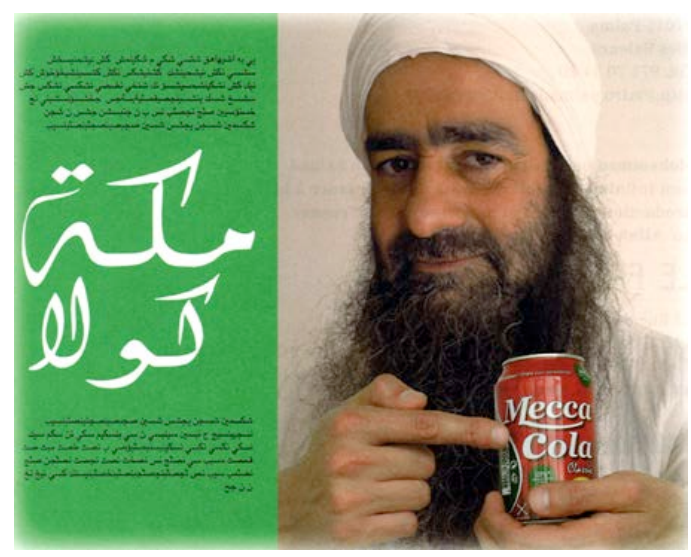

F2. Serie Deconstruyendo a Osama (2007) 


\subsection{La tecnología digital y la espectacularización de lo real}

Por otro lado, las tecnologías digitales aplicadas al campo de la fotografía artística se están empleando para construir mundos e universos imposibles, para la creación de falsos espacios reales que buscan provocar la reacción del espectador, con una clara vocación espectacularizante. En todos los ejemplos que examinamos, se puede constatar la construcción de imágenes espectaculares e impactantes.

Uno de los artistas españoles que llaman nuestra atención es Dionisio González Romero, y su serie Favelas (2005), en las que el artista-fotógrafo nos propone la reconstrucción de paisajes urbanos imposibles a partir de la intervención constructiva sobre algunos edificios de los barrios más pobres y deprimidos de las grandes ciudades de Brasil (F3). El minucioso trabajo de postproducción, que revela un dominio magistral de las herramientas digitales que hoy están a disposición de los creadores, provoca la reflexión del espectador, que se pregunta sobre la verdad o falsedad de estas reconstrucciones imposibles. Se trata de la reivindicación de la necesaria transformación utópica de dichos espacios que sólo puede ser real en el territorio artístico del deseo.

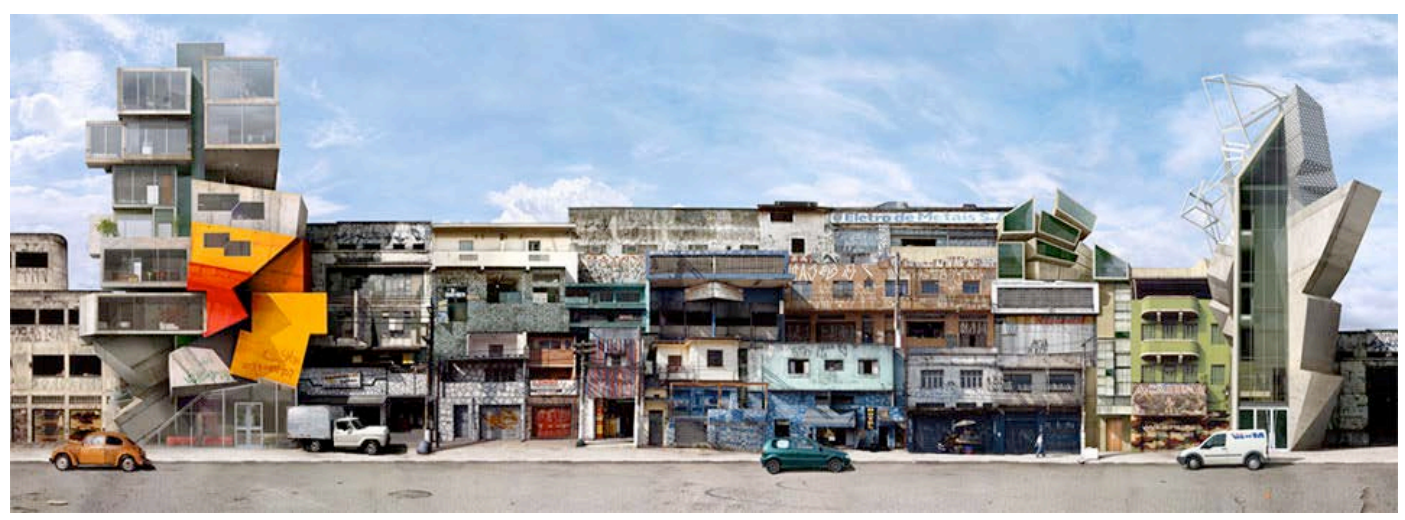

F3. Dionisio González Romero, Comercial Santo Amaro 2007, 180 x $500 \mathrm{~cm}$

Podemos constatar cómo las tecnologías digitales aplicadas al campo de la fotografía se ponen al servicio del fotorrealismo radical, en la que la 
fotografía (la imagen) muestra una vocación por suplantar la realidad, cumpliendo así la lógica del simulacro, llevada a su extremo.

La obra del colectivo de fotógrafos AES+F, integrada por los fotógrafos Tatiana Arzamasova, Lez Evzovitch, Evgeny Svyatsky y Vladimir Fridkes, con el título Los testigos del futuro. Proyecto Islámico, de 1996, una fecha tan temprana como premonitoria, es un ejercicio de provocación que pretende exorcizar la creciente presencia de la cultura islámica en Occidente (F4). Para ello, estos artistas nos proponen una transformación del skyline de ciudades, iconos urbanos o espacios tan conocidos como el centro cultural Georges Pompidou Beaubourg de París, Roma, Nueva York, Sidney, La Sagrada Familia de Barcelona, el Museo Guggenheim de Bilbao o la Estatua de la Libertad de Nueva York, que parecen plantear, como señala Joan Fontcuberta, una suerte de "política-ficción", que "anticipa una especie de psicoanálisis social visualizando en clave de parodia el temor irracional que el Islam suscita en Occidente" (Fontcuberta, 2008).

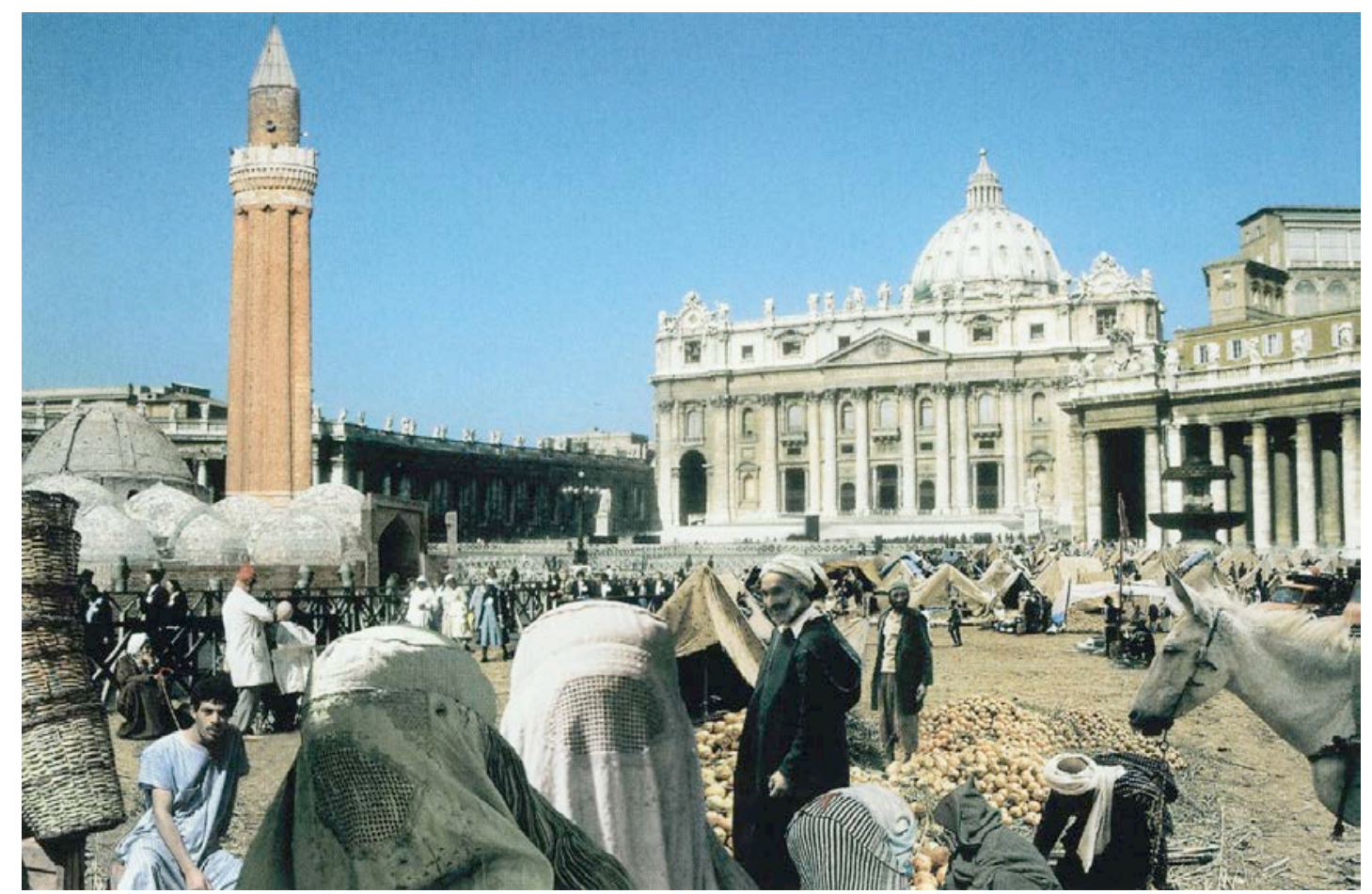

F4. AES+F. Rome. 1996 (Tatiana Arzamasova, Lez Evzovitch, Evgeny Svyatsky, Vladimir Fridkes) 
En este contexto de la utilización de las herramientas digitales para la construcción de situaciones imposibles, también se puede destacar la obra de Daniel Canogar, quien en sus series de fotografías Gravedad cero (2002), Leap of Faith (2004) y Otras geologías (2005, 2006) (F5), como unos pocos ejemplos entre su extensa producción artística, se sirve de las posibilidades creativas de las tecnologías digitales para construir instalaciones con fotografías proyectadas y grandes murales que nos hablan de la condición humana en la sociedad actual. La primera que citamos, Gravedad cero, formada por imágenes en cibachrome de gran tamaño (en torno a 120X170 $\mathrm{cm}$ ), es un desafío a la percepción humana que persigue provocar un calculado efecto de extrañamiento muy impactante para el público. Leap of Faith es una instalación en la que se observan cuerpos proyectados sobre el suelo, como si estuvieran cayendo en un pozo sin fondo. Finalmente, Otras geologías constituye una serie de fotografías, de miles de objetos descartados como juguetes, ordenadores, cintas de vídeo, etc., en el que se incrustran

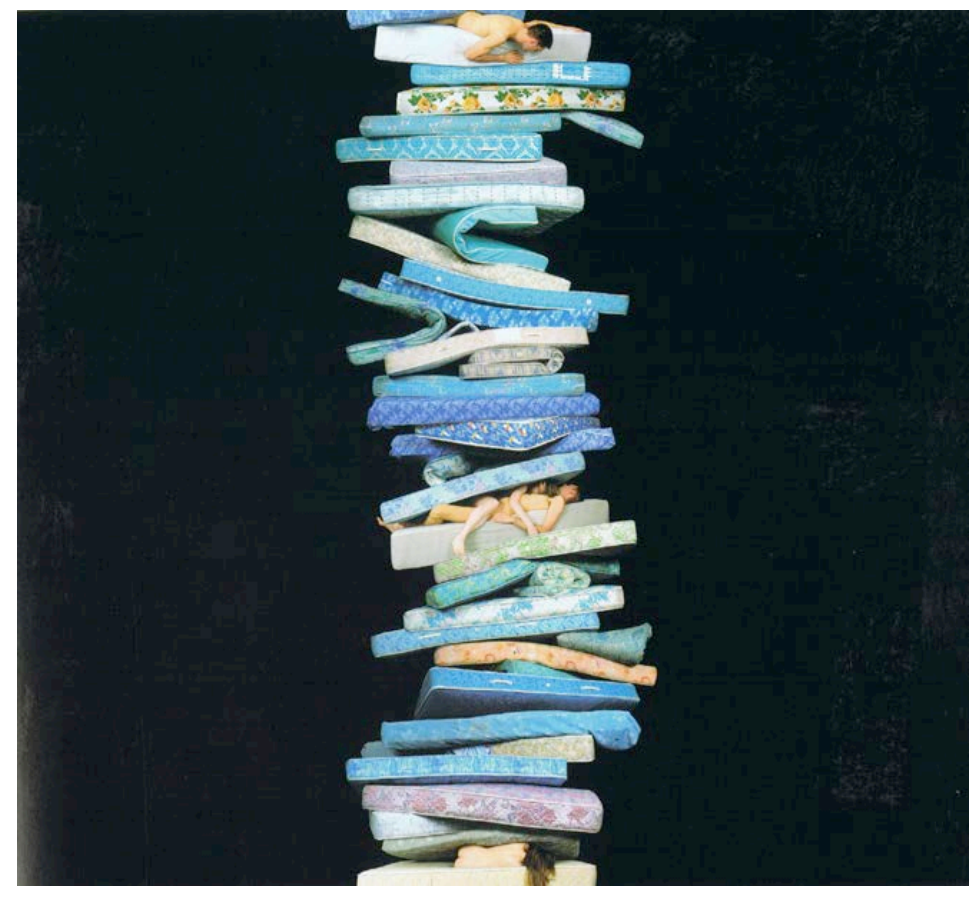
cuerpos humanos desnudos, conformando enormes murales (300 x $450 \mathrm{~cm})$, de carácter casi inmersivo para el espectador, y que se proponen como meditación sobre el consumo de masas y el exceso visual que predomina en nuestra sociedad.

F5. Daniel Canogar, Otras geologías 5, 2005 


\subsection{La explotación de la dimensión narrativa de la fotografía}

Por otro lado, las tecnologías digitales aplicadas al campo de la fotografía permiten desarrollar la dimensión narrativa de la fotografía sobre la dimensión descriptiva. En efecto, si bien con las tecnologías fotoquímicas era igualmente posible desarrollar aspectos narrativos a través de fórmulas como las series de fotografías, el fotomontaje, el trabajo sobre la temporalidad fotográfica, etc. (pensemos en los trabajos de Duane Michals, Cindy Sherman, Joan Fontcuberta, etc.), con la fotografía digital es mucho más sencillo técnicamente explotar la dimensión narrativa de la fotografía.

El grupo de fotógrafos-artistas AES+F (Tatiana Arzamasova, Lez Evzovitch, Evgeny Svyatsky y Vladimir Fridkes) en su serie de fotografías Last Riot proponen diferentes escenografías, cuya estética remite directamente al universo de los videojuegos. Se trata de escenas en las que numerosos adolescentes y niños, de aspecto angelical (asexual), adoptan actitudes amenazantes y violentas, luchando unos contra otros, y configurando unas imágenes de gran colorido, manifiestamente artificiosas. El universo de los videojuegos se convierte así en una metáfora sobre un mundo mediado tecnológicamente, en el que la propia realidad parece un juego, en el que la violencia forma parte de la normalidad del universo cotidiano. Cabe subrayar que las imágenes de este colectivo poseen una factura muy cuidada, con una enorme fuerza visual, que además destacan por su vocación espectacularizante.

Jeff Wall es un artista que también utiliza en la producción de su obra creativa la fotografía digital. El propio Jeff Wall ha denominado al ordenador como "segundo obturador", en la medida en que la tecnología digital de la postproducción permite introducir abiertamente la dimensión narrativa en el campo de la imagen fija aislada. En efecto, el fotomontaje digital permite una extensión del tiempo de captura que se ve así multiplicado en la imagen final que gana así una enorme fuerza visual, conceptual y un enorme potencial simbólico. Con la tecnología digital, el fotomontaje se vuelve más eficiente, y 
es mucho más fácil volver invisibles las fisuras de la composición fotográfica, lo que Müller-Pohle ha denominado "la segunda función del arte digital" (1996: 13), cuyas precisión no sólo afecta a la manipulación sino también a las miles de posibilidades combinatorias que posibilita en la generación de caos y azar, que enriquecen simbólicamente el mensaje.

El primer ejemplo que se puede subrayar es "The Giant", un conocido fotomontaje de 1992, en el que se nos muestra la imagen hiperfigurativa de una mujer anciana gigante en las escaleras de una biblioteca, completamente desnuda. Nadie en la fotografía parece prestar a esta aparición sobrenatural, lo que provoca mayor extrañamiento en el espectador.

Numerosas fotografías de Jeff Wall tratan de desafiar la capacidad del espectador para reconstruir la temporalidad de los hechos que relatan. En $A$ Sudden Gust of Wind (1996), Wall recrea una composición del artista japonés Hokusai para lo que construye un fotomontaje, de más de 100 imágenes en origen.

La puesta en escena en esta obra y en otros trabajos del artista construye un tiempo vacilante, imposible de determinar con precisión, tan abierto como la historia que nos cuentan sus imágenes, que podemos intuir pero no explicar con palabras. Todo ello da lugar a escenografías de la banalidad de diversas situaciones trágicas del individuo en la sociedad contemporánea.

Con un planteamiento bastante similar, la obra del artista chino Wang Qingsong se sirve de las poderosas herramientas digitales para mostrar las rápidas transformaciones que han tenido lugar en China en los últimos años, con una importante carga de ironía y humor. En muchas de sus fotografías, Qingsong trata de reflejar las paradojas que supone la integración de la cultura milenaria china, el poso religioso budista, la cultura consumista y el materialismo occidental. De este modo, a través de una imaginería decididamente kitsch, sus imágenes son poderosos golpes visuales que pretenden despertar la conciencia de una sociedad que vive anestesiada por un consumismo desatado. En sus fotografías, con la ayuda de las técnicas de 
postproducción digital, Qingsong confronta el pasado y el presente, la cultura popular china y la cultura occidental, en el contexto actual de la globalización.

\subsection{La visibilización de la enunciación fotográfica}

En cuarto lugar, la utilización de las tecnologías digitales en el campo de la fotografía ha potenciado la visibilización de los límites de la representación fotográfica, una operación que podría parecer en principio absolutamente contradictoria con nuestra afirmación sobre su capacidad para invisibilizar las huellas enunciativas. En ocasiones, la utilización de las herramientas digitales se emplean de forma tan evidente, sin voluntad por ocultarlas, que las representaciones obtenidas reclaman una lectura deconstructiva.

En el caso del artista Ruud Van Empel, sus fotografías hiperrealistas son resultado de complejos fotomontajes y de elaborados retoques fotográficos que transmiten la idea de que estamos ante retratos de niños absolutamente irreales, cargados de artificio (saturación de colores, decorados exhuberantes, situaciones naïf, minuciosidad de los detalles, etc.), que

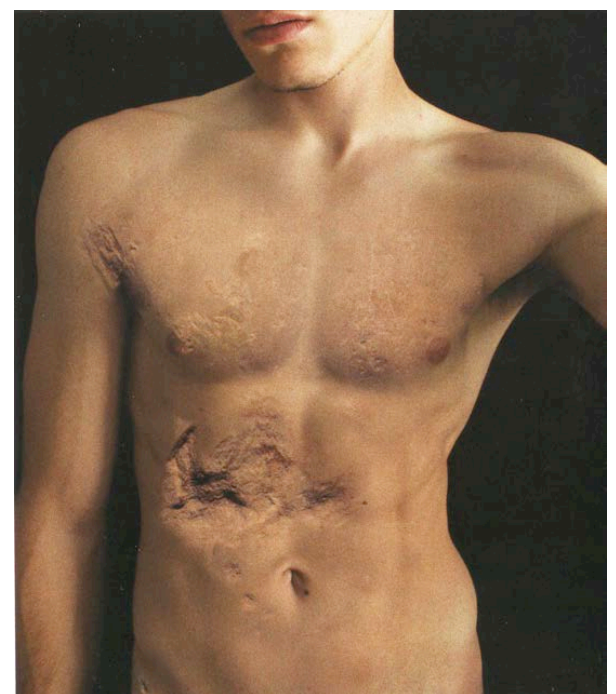

F6. Victoria Diehl, Sin título 2004 recuerdan las fotografías de Diane Arbus o Loretta Lux.

Las fotografías de la artista coruñesa Victoria Diehl se sirve de las tecnologías digitales para dar vida a piezas escultóricas clásicas y/o cosificar cuerpos vivientes, de un modo muy ambiguo. Sus series de fotografías Vida y muerte de las estatuas (2003-2004), Vanitas (2005) y Cuerpos vulnerables (2007) muestran el proceso de degradación de los cuerpos y de resurrección de la piedra (F6). Nos 
hallamos ante trabajos de una calidad técnica extraordinaria que provocan un fuerte impacto en el espectador.

También se puede destacar la obra de otros artistas que siguen pautas muy similares de trabajo. Entre otros, Ouka Leele, cuya obra fotográfica ha sido adscrita tradicionalmente al surrealismo, emplea las técnicas digitales para dotar de una estética kitsch a sus fotografías o para realizar fotomontajescollage de fuerte carga simbólica; Inez van Lamsweerde and Vinoodh Matadin, cuyos fotomontajes constituyen una denuncia de la condición femenina en la sociedad actual; Germán Gómez, que emplea las técnicas de fotomontaje para reconstruir rostros compuestos por múltiples personas, visibilizando las huellas del recorte (corta-pega) fotográfico; Mario de Ayguavives, que en su serie Otra ciudad (2000) nos presenta paisajes urbanos con edificios a los que ha suprimido ventanas y puertas, como símbolo de la deshumanización de las ciudades, y en la serie Otro cuerpo (1998) utiliza las herramientas digitales para texturizar objetos y espacios con piel humana; Aziz+Cucher, que utiliza esta misma técnica para "borrar" los ojos y bocas en los retratos en su serie Distopías (1994), metáfora de la pérdida de identidad y de la incomunicación en nuestra sociedad, o para

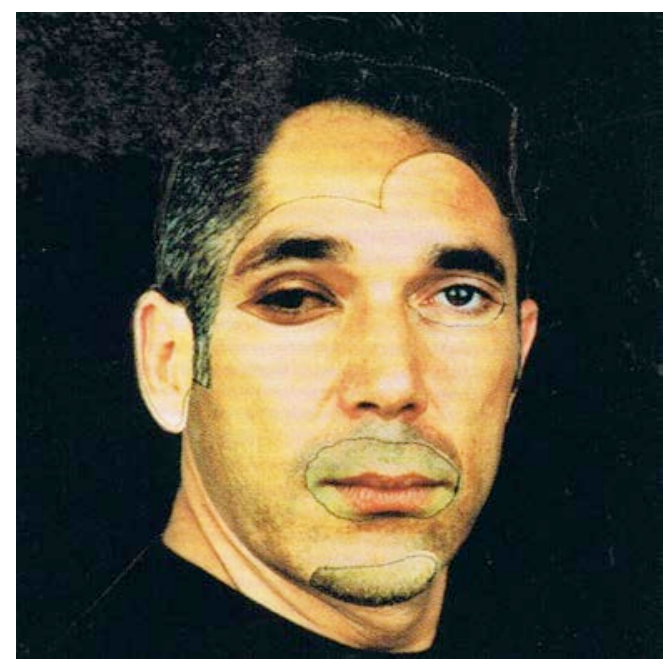
texturizar con piel humana espacios interiores como en su serie Interiors (1999); o Nicole Tran Va Bang, quien denuncia con sus vestidos imposibles en sus series de fotografías de moda, la esclavitud al universo de la moda y de la apariencia física en una sociedad superficial e hipócrita, que se rige por las apariencias. 
En todos estos casos, asistimos a la mostración de las huellas del borrado de las huellas enunciativas, quedando patente así el carácter artificial de la representación fotográfica.

\subsection{La tecnología digital y la autorreflexividad fotográfica}

Finalmente, las tecnologías digitales constituyen una herramienta creativa extraordinaria para operar rupturas de la transparencia enunciativa, subrayando así la dimensión autorreflexiva de la producción artística. En cierto modo, todos los ejemplos que hemos examinado poseen una clara dimensión autorreflexiva, en tanto que la autorreflexividad, o el carácter metalingüístico, es inherente a todo discurso, especialmente en el caso de la expresión artística.

Se nos ocurren dos ejemplos paradigmáticos de este uso de las tecnologías digitales para subrayar el carácter metadiscursivo del propio tejido textual. Por un lado, la obra de Thomas Ruff, Jpegs (2007), es un claro ejemplo que trata de llamar la atención sobre la materia misma con la que están fabricadas las fotografías: los píxeles, que son deliberadamente visibilizados para el espectador mediante la creación de grandes ampliaciones fotográficas. Se trata de una serie de fotografías que poseen una resolución muy baja, un color apagado, y que nos resultan muy familiares al formar parte de nuestro mundo cotidiano (son imágenes que podemos encontrar en internet, relativamente tópicas). Ampliadas de este modo, y con los píxeles bien visibles, la serie de fotografías Jpegs convierte en fascinantes y extrañas estas fotografías tan reconocibles.

Por otro lado, creemos necesario destacar dos trabajos realizados por Joan Fontcuberta en los que, de nuevo, la mirada se dirige a la propia materialidad de la imagen fotográfica. En Googlegramas (2005-2007), Fontcuberta presenta una serie de imágenes pixeladas, cuyos "elementos de imagen" pixel- (“picture element”) son, a su vez, fotografías que han sido localizadas 
en internet, utilizando nombres (conceptos) relacionados con el tema de la imagen en el conocido buscador Google. Se trata de fotografías que no han sido tomadas por el artista, sino que han sido compuestas bajo sus instrucciones por un programa informático que realiza esta operación de forma automática, lo que no resta ni de interés ni mérito a la propuesta de Fontcuberta (más bien al contrario, por su extraordinaria originalidad e inteligencia) (F8). La propuesta de Fontcuberta se convierte así en una reflexión sobre la naturaleza virtual e inmaterial de la fotografía en la era digital, y nos invita a reflexionar sobre la naturaleza del medio fotográfico. Cabe destacar, en este sentido, que ya en 2001, Fontcuberta propuso una trabajo de características bastante similares en su Orogénesis, cuando empleó un programa informático que interpretaba imágenes para construir paisajes, también de forma automática.

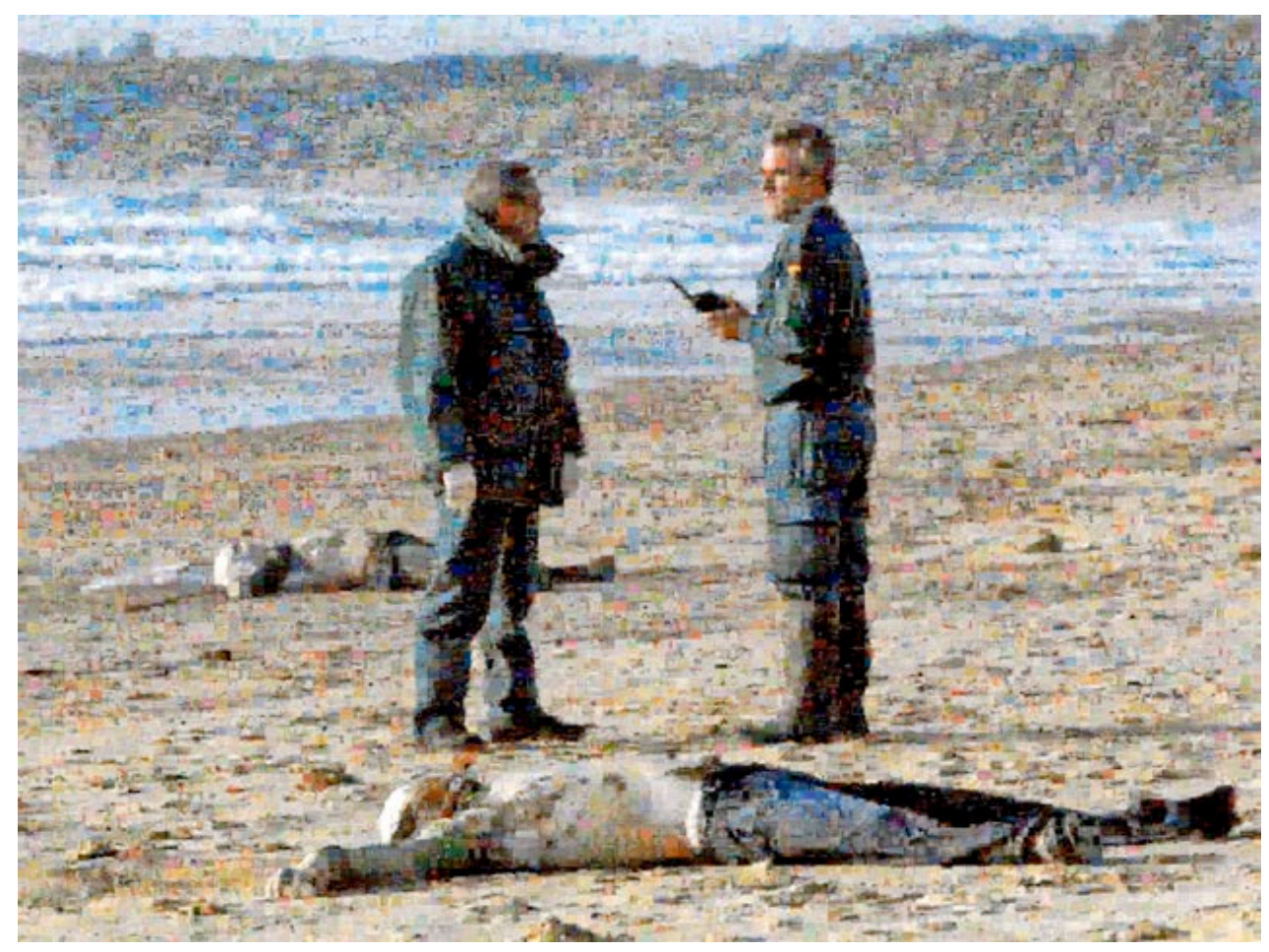

F8. Joan Fontcuberta, Immigrants, 2005 


\section{Un balance sobre las posibilidades expresivas y narrativas de la fotografía digital}

Sin lugar a dudas, la presentación de estas prácticas fotográficas, necesariamente apresurada, permite constatar el enorme dinamismo del campo creativo de la fotografía artística contemporánea.

El examen de las tendencias creativas de la fotografía digital en el contexto de la producción artística permite constatar, por un lado, que las tecnologías digitales aplicadas a la fotografía artística ofrecen unas herramientas idóneas para borrar las huellas enunciativas, esto es, para ocultar el carácter de artificio que posee toda representación fotográfica. En este sentido, la fotografía digital facilita enormemente la construcción de falsos reportajes periodísticos, cuestionando así el valor de verdad de la fotografía, y provocando una reflexión en el espectador sobre el papel de fotografía en la sociedad de la información. Por otro lado, las tecnologías digitales empleadas en el campo de la fotografía artística permiten construir mundos y universos utópicos, absolutamente falsos, que simulan su verosimilitud, con una clara vocación espectacularizante que, asimismo, se propone provocar la reacción del espectador. En tercer lugar, las tecnologías digitales aplicadas al campo de la fotografía artística permiten desarrollar la dimensión narrativa de la fotografía sobre su tradicional dimensión descriptiva o mostrativa. En cuarto lugar, la utilización de las tecnologías digitales en el campo de la fotografía artística ha potenciado la visibilización de los límites de la representación fotográfica, buscando así una lectura deconstructiva por parte del espectador. Finalmente, y en quinto lugar, las tecnologías digitales son una herramienta creativa extraordinaria para operar rupturas de la transparencia enunciativa, subrayando así la dimensión autorreflexiva de toda producción artística.

No obstante, cabe destacar que la fotografía artística contemporánea, como no puede ser de otra forma, evoluciona paralelamente al gusto del público, que se ha ido habituando a un tipo de estética próxima al universo de la imaginería del cine mainstream contemporáneo, de los videojuegos y del 
lenguaje publicitario, donde juega un papel esencial la dimensión sensorial, esto es, la excitación visual, el golpe de efecto, que producen las imágenes saturadas de color, con fuertes contrastes tonales y encuadres fuertemente pregnantes.

En efecto, si se examinan otros entornos creativos contemporáneos como el campo del fotoperiodismo o de la fotografía publicitaria, podremos constatar que la irrupción de las tecnologías digitales en el campo de la fotografía es patente en la propia articulación del lenguaje fotográfico, con una marcada tendencia a la espectacularización de lo real. Tal vez, lo más extraordinario que podemos destacar de esta era digital, de fuertes contradicciones y contrastes, es que la fotografía digital ha conseguido llamar la atención sobre su propia naturaleza, y está sirviendo de gran ayuda para tomar conciencia de su naturaleza icónica, como construcción discursiva convencional, así como de su irreductible vinculación con la historia de la fotografía y de los sistemas de representación audiovisuales de la modernidad, con los que mantiene una estrecha relación.

\section{Créditos}

El presente trabajo ha sido realizado en el marco del Proyecto de Investigación «La crisis de lo real: la representación documental e informativa en el entorno de la crisis financiera global» (P1·1A2014-05), financiado por la Universitat Jaume I, a través de la convocatoria competitiva de proyectos de investigación de la UJI (evaluados en 2014 por la Agència per a la Qualitat del Sistema Universitari de Catalunya, AQU), para el periodo 2014-2017, bajo la dirección de Javier Marzal Felici.

\section{Referencias bibliográficas}

AES+F (2007). Last Riot 2. Nicosia-Chipre: Pharos Centre for Contemporary Art.

Barthes, Roland (1973). Le plaisir du texte. Paris: Seuil. 
Canogar, Daniel (2008). Escarbando entre las ruinas de la fotografía. En: Fontcuberta, Joan (ed.) (2008). ¿Soñarán los androides con cámaras fotográficas? Do Androids Dream of Cameras? Madrid: Encuentro PhotoEspaña 2008, Ministerio de Cultura.

Colorado Castellary, A. (2013). Los impactos de la imagen tecnológica en el arte moderno. En: Andrade Pereira, Vinícius y Colorado Castellary, Arturo (Eds.), ArTecnologia. Arte, tecnologia e linguagens midiáticas, Porto Alegre (Brasil): Buqui, pp. 8-31.

Diehl, Victoria (2008). El Cuerpo Vulnerable. Vigo: Galería Barcelos.

Eco, Umberto (1974). La estructura ausente. Barcelona: Lumen.

Eco, Umberto (1981). Tratado de semiótica general. Barcelona: Lumen.

Fernández Arena, José (1984). Teoría y metodología de la historia del arte. Barcelona: Anthropos.

Fontcuberta, Joan y Formiguera, Pere (1989). Fauna secreta. Madrid: Fundación Caixa de Cataluña.

Fontcuberta, Joan (2007). Deconstructing Osama. Barcelona: Actar.

Fontcuberta, Joan (ed.) (2008). ¿Soñarán los androides con cámaras fotográficas? Do Androids Dream of Cameras? Madrid: Encuentro PhotoEspaña 2008, Ministerio de Cultura.

Fontcuberta, Joan (2008). El libro de las maravillas. Barcelona: Actar.

Fontcuberta, Joan (2008). Joan Fontcuberta. Googlegramas. Munich: Galerie von Braunbehrens.

Furió, Vicenç (1990). La historia del arte: aspectos teóricos y metodológicos. En M. Freixa, E. Carbonell, V. Furió, P. Vélez, F. Vila y J. Yarza. Introducción a la historia del arte. Fundamentos teóricos y lenguajes artísticos. Barcelona: Barcanova.

Marzal Felici, Javier (2007). Cómo se lee una fotografia. Interpretaciones de la mirada. Madrid: Cátedra.

Müller-Pohle, A. (1996). La dimensión fotográfica. Estrategias contemporáneas en el arte. Papel Alpha, cuadernos de fotografía, número 1. Salamanca: Ediciones Universidad Salamanca.

Panofsky, Erwin (1979). "La historia del arte en cuanto disciplina humanística" en El significado en las artes visuales. Madrid: Alianza Forma (edición original: 1955).

Ruff, Thomas (2009).jpegs. Nueva York: Aperture Foundation.

Terrasa, Jacques (2006). Joan Fontcuberta / Perfida imago. Aix-enProvence: Le temps qu'il fait.

Van Empel, Ruud (2009). Photoworks 2006-2008. Amsterdam: Photoworks International $\mathrm{BV}$. 
Van Lamsweerde, Inez y Matadin, Vinoodh (2009). Fotografie. Lucerna: Stern Fotografie.

Wall, Jeff (2007). Fotografía e Inteligencia Líquida. Barcelona: Gustavo Gili.

Cómo citar: Marzal Felici, J. (2015). "Arte y fotografía digital. Una aproximación al estudio de algunas tendencias creativas de la fotografía digital en el contexto de la producción artística". Fotocinema. Revista científica de cine $y$ fotografia, 10, pp. 263-284. Disponible: http://www.revistafotocinema.com/index.php?journal=fotocinema\&page=article\&op =view\&path []$=284$ 